\title{
elF2a-CHOP-BCl-2/JNK and IRE1a-XBP1/JNK signaling promote apoptosis and inflammation and support the proliferation of Newcastle disease virus
}

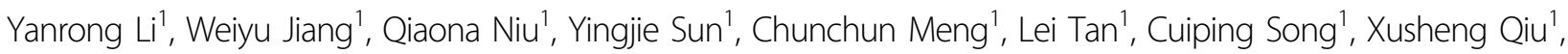 \\ Ying Liao ${ }^{1}$ and Chan Ding ${ }^{1,2}$
}

\begin{abstract}
Newcastle disease virus (NDV) causes severe infectious disease in poultry and selectively kills tumor cells, by inducing apoptosis and cytokines secretion. In this report, we study the mechanisms underlying NDV-induced apoptosis by investigating the unfolded protein response (UPR). We found that NDV infection activated all three branches of the UPR signaling (PERK-elF2a, ATF6, and IRE1a) and triggered apoptosis, in avian cells (DF-1 and CEF) and in various human cancer cell types (HeLa, Cal27, HN13, A549, H1299, Huh7, and HepG2). Interestingly, the suppression of either apoptosis or UPR led to impaired NDV proliferation. Meanwhile, the inhibition of UPR by 4-PBA protected cells from NDV-induced apoptosis. Further study revealed that activation of PERK-elF2a induced the expression of transcription factor $\mathrm{CHOP}$, which subsequently promoted apoptosis by downregulating $\mathrm{BCL}-2 / \mathrm{MCL}-1$, promoting JNK signaling and suppressing AKT signaling. In parallel, IRE1 a mediated the splicing of XBP1 mRNA and resulted in the translation and nuclear translocation of XBP1s, thereby promoting the transcription of ER chaperones and components of ER-

associated degradation (ERAD). Furthermore, IREla promoted apoptosis and cytokines secretion via the activation of JNK signaling. Knock down and overexpression studies showed that CHOP, IRE1a, XBP1, and JNK supported efficient virus proliferation. Our study demonstrates that the induction of elF2a-CHOP-BCL-2/JNK and IRE1 a-XBP1/JNK signaling cascades promote apoptosis and cytokines secretion, and these signaling cascades support NDV proliferation.
\end{abstract}

\section{Introduction}

The endoplasmic reticulum (ER) plays an important role in regulating protein synthesis/processing, lipid synthesis, and calcium homeostasis ${ }^{1}$. During virus infection, many viral proteins are synthesized by ER-associated ribosome and transported into the ER lumen for proper folding or posttranslational modification. This leads to an

\footnotetext{
Correspondence: Ying Liao (liaoying@shvri.ac.cn) or Chan Ding

(shoveldeen@shvri.ac.cn)

'Department of Avian Diseases, Shanghai Veterinary Research Institute,

Chinese Academy of Agricultural Sciences, Shanghai 200241, P. R. China

${ }^{2}$ Jiangsu Co-innovation Center for Prevention and Control of Important Animal

Infectious Diseases and Zoonoses, Yangzhou 225009, P. R. China

These authors contributed equally: Yanrong Li, Ying Liao

Edited by $\mathrm{H}$. Häcker
}

overwhelming load of unfolded or misfolded proteins in the ER lumen. The chaperone Bip then binds to these unfolded/misfolded proteins and releases the ER stress sensors PERK, ATF6, and IRE1 $\alpha$, triggering unfolded protein response (UPR). PERK is activated by autophosphorylation and in turn phosphorylates eIF2 $\alpha$ on Ser $51^{2,3}$. Phospho-eIF $2 \alpha$ has increased affinity to the eIF2 $\beta$ subunit and prevents the regeneration of guanosine triphosphate (GTP) in the ternary complex eIF2GTP- ${ }^{\text {Met }}$ tRNAi, thus halting the initiation of protein translation ${ }^{4}$. However, ATF4 mRNA is preferentially translated and promotes the transcription of genes important for cellular remediation or apoptosis, including $\mathrm{CHOP}^{5}$. Another eIF2 $\alpha$ kinase, PKR, also elicits eIF2 $\alpha$ -

\section{(c) The Author(s) 2019}

(c) (i) Open Access This article is licensed under a Creative Commons Attribution 4.0 International License, which permits use, sharing, adaptation, distribution and reproduction c. in any medium or format, as long as you give appropriate credit to the original author(s) and the source, provide a link to the Creative Commons license, and indicate if changes were made. The images or other third party material in this article are included in the article's Creative Commons license, unless indicated otherwise in a credit line to the material. If material is not included in the article's Creative Commons license and your intended use is not permitted by statutory regulation or exceeds the permitted use, you will need to obtain permission directly from the copyright holder. To view a copy of this license, visit http://creativecommons.org/licenses/by/4.0/. 
ATF4-CHOP signaling in response to virus infection ${ }^{6-8}$. ATF6 dissociates from Bip and moves to the Golgi apparatus, where it is cleaved into $\mathrm{N}$-terminal fragment ATF6-N and subsequently translocated to the nucleus as an active transcription factor, triggering the transcription of protein chaperones and components of ER-associated degradation (ERAD) $)^{9-11}$. The IRE1 $\alpha$-XBP1 branch is the most evolutionarily conserved in Eukarya ${ }^{12}$. After dissociating from Bip, IRE1 $\alpha$ undergoes homooligomerization and autophosphorylation, obtaining both kinase and endoribonuclease activity ${ }^{13}$. This endoribonuclease leads to unconventional enzymatic splicing of XBP1u mRNA into XBP1s by removing the 26-nucleotide intron. The spliced mRNA is then translated into transcription factor XBP1s, controlling the expression of the ER quality control genes and components of ERAD ${ }^{11,13-15}$. IRE1 $\alpha$ also degrades ER-associated mRNAs to attenuate protein load in the ER lumen ${ }^{16}$.

If ER homeostasis cannot be restored, UPR drives the damaged or infected cells to apoptosis ${ }^{17}$. Apoptosis is triggered by either intrinsic signaling or extrinsic death ligands. The intrinsic pathway is under the control of the BCL-2 protein family ${ }^{18}$. Pro-survival guardian proteins (BCL-2, MCL-1, and BCL-xL) inhibit apoptosis through binding and sequestering pro-apoptotic activators (BID, BIM, PUMA, and NOXA) or effectors (BAX and BAK). When enough activators have been stimulated by cytotoxic stresses, BAX is released from pro-survival guardian proteins and oligomerizes to form pores on the mitochondrial outer membrane, thereby releasing cytochrome c and activating caspase $9^{19-21}$. Under persistent ER stress, the induction of $\mathrm{CHOP}$ may promote cell apoptosis by regulating the expression of BCL-2, TRB3, death receptor 5, ERO1 $\alpha$, and GADD34, and perturbing the cellular redox state ${ }^{22-24}$. IRE1 $\alpha$ may promote apoptosis through interacting with TRAF2 and ASK1, in turn activating pro-apoptotic $\mathrm{JNK}^{25}$. Prolonged UPR is also an inflammatory nidus and may elicit a defensive innate immune response against the invading pathogen. Activation of IRE1 $\alpha$-JNK leads to the increased expression of pro-inflammatory cytokines ${ }^{26}$. NF- $\mathrm{KB}$ is activated by IRE1 $\alpha$-TRAF2 mediated IкB phosphorylation and degradation ${ }^{27}$. In another way, when protein translation is halted by PERK-eIF2 $\alpha$ signaling, the ratio of NF-кB to ІкB is increased, and NF-KB is then released and activated ${ }^{28,29}$.

Newcastle disease virus (NDV) is a highly contagious avian pathogen belonging to the genus Avulavirus within the family Paramyxoviridae ${ }^{30}$. NDV infection caused death of chicken embryos and neurological damage in adult chicken are the consequences of apoptosis and inflammation ${ }^{31}$. NDV also selectively infects the human cancer tissues, kills cancer cells directly or attracts immune cells to remove the infected tumor cells ${ }^{32}$. Although several reports show that NDV infection results in the loss of mitochondrial membrane potential ${ }^{33-36}$ and the induction of extrinsic death ligands TNF- $\alpha /$ TRAIL $^{37}$, the intrinsic death signals are yet to be fully clarified. We have reported that NDV infection-induced phosphorylation of eIF2 $\alpha$ results in shut off of protein translation ${ }^{38}$. In this study, we focused on characterization of the UPR branches and their roles in NDV- triggered apoptosis and inflammation, in several human cancer cell types and avian cells.

\section{Materials and methods \\ Cells and virus}

The human cervical cancer cell line (HeLa), human non-small cell lung cancer cell lines (A549 and H1299), chicken embryo fibroblast monolayer cell line (DF-1), and human embryonic kidney cell line (293T) were purchased from ATCC (Manassas, VA, USA). Tongue squamous carcinoma cell line (CAL27), squamous cell carcinoma of oral cancer cell line (HN13), and human hepatocellular carcinoma cell lines (Huh7 and HepG2) were provided by Prof. Lijun Jia (Shanghai University of Chinese Medicine, shanghai, China). These cells were cultured in Dulbecco's modified Eagle's medium (DMEM) (Hyclone, USA), RPMI 1640, or F-12K medium supplemented with $10 \%$ fetal bovine serum (FBS, Gbico, USA) at $37^{\circ} \mathrm{C}$ humidified atmosphere containing $5 \% \mathrm{CO}_{2}$. Chicken embryo fibroblasts (CEFs) were derived from 10-days-old SPF chicken embryos which bought in MERIAL (France).

The NDV velogenic strain Herts/33 was obtained from China Institute of Veterinary Drug Control (Beijing, China). The virus was propagated in chicken embryonated eggs and titrated on DF-1 cells by $\mathrm{TCID}_{50}$ assay. The virus was used for infection at the multiplicity of infection (MOI) of 1 throughout this study.

\section{Reagents and antibodies}

The IRE1 $\alpha$ inhibitor 8-formyl-7-hydroxy-4-methylcoumarin $(4 \mu 8 \mathrm{c}) \quad$ (s7272), PKR/PERK inhibitor GSK2606414 (s7307), JNK inhibitor SP600125 (s1460), ERK1/2 inhibitor U0126 (s1102), p38 inhibitor SB203580 (s1076) and AKT inhibitor LY294002 (s1105) were purchased from Selleck Chemicals (USA). 4phenylbutyric acid (4-PBA) (B26966) was purchased from YuanYe Biological Company (China). RNA extraction reagent TRIzol $^{\circledR}$, transfection reagent Lipofectamine 2000, Click-iTTM Plus TUNEL Apoptosis Assay Kit (C10617), and Dead Cell Apoptosis Kit with Annexin V Alexa Fluor ${ }^{\mathrm{TM}} 488$ \& Propidium Iodide (PI) (V13245) were purchased from Invitrogen Thermo Fisher Scientific (USA). Western blot stripping buffer (p0025) and 4',6'-diamidino-2-phenylindole (DAPI) (c1002) were purchased from Beyotime Biotechnology (China). SYBR Green qPCR Mix (p2092) was purchased from Dongsheng Biotech (China). 
Monoclonal NDV NP antibody was raised in mice using bacterially expressed His-tagged NP as the immunogen. Antibodies against Caspase-3 (9665), PARP (9542), PERK (5683), phospho-eIF2 $\alpha$ (3398), eIF2 $\alpha$ (5324), IRE1 $\alpha$ (3294), ATF6 (65880, used for western blot), CHOP (2895), PKR (12297), BCL-2 (4223), MCL-1 (5453), BCLxL (2764), BIM (2933), PUMA (12450), BAX (5023), phospho-AKT (13038), AKT (4691), phospho-JNK (4668), JNK (9252), phospho-p38 (4511), p38 (8690), phospho-ERK1/2 (4370), ERK1/2 (4695), TBK1(3504), phospho-TBK1 (5483), IRF3 (11904), p65 (8242), and phospho-p65 (3033) were purchased from Cell Signaling Technology (USA). Phospho-PERK (DF7576) was purchased from Affinity Biosciences. Phospho-IRE1 $\alpha$ (ab48187), XBP1 (ab37152), phospho-PKR (ab32506), phospho-IRF3 (ab76493), and ATF6 (ab122897, used for immunofluorescence) were purchased from Abcam (UK). Anti-Flag and $\beta$-actin (A1978) were purchased from Sigma-Aldrich (USA). The secondary IgG conjugated with HRP, FITC, or TRITC were obtained from DAKO (Denmark).

The specific sequences of small interfering RNA (siRNA) oligos of caspase-3, PERK, PKR, CHOP, AKT, JNK, p38, ERK1/2, IRE1 $\alpha, \mathrm{XBP} 1$, and non-target control siRNA (sic) were shown in Table 1. All siRNAs were synthesized by Gene Pharma Co. Ltd (Shanghai, China).

\section{Tissue culture infectious dose $50\left(\mathrm{TCID}_{50}\right)$ assay}

Virus yield in culture medium of NDV-infected cells was determined by measuring $\mathrm{TCID}_{50}$ in DF-1 cells. In brief, DF-1 cells were seeded in 96-well plates at a density of $2.0 \times 10^{4}$ cells per well. After $24 \mathrm{~h}$, cells were infected with virus, which was serially diluted in 10 -fold using

Table 1 Small interfering RNA (siRNA) sequence.

\begin{tabular}{ll}
\hline Name & Sequence (5'-3) \\
sic & UUCUCCGACGUGUCACGUTT \\
siPERK & GGUUGGAGACUUUGGGUUAU \\
siPKR & GCGAGAAACUAGACAAAGUUU \\
siCHOP & GAGCUCUGAUUGACCGAAUTT \\
silRE1a & CUCCGAGCCAUGAGAAUATT \\
siXBP1 & GGAACAGCAAGUGGUAGAUTT \\
siCASP3 & GCAUAUCAGUUGAGCUUCATT \\
siAKT & GAAGGAGUCAUCGUGGCCUU \\
siERK1 & UGA CCA CAU CUG CUA CUU C \\
siERK2 & GUG CUG UGU CUU CAA GAG C \\
sip38 & GAACUGCGGUUAUUAAC \\
siJNK & AAAGAAUGUCCUACCUUCUUU \\
\hline
\end{tabular}

sic Non-target control siRNA, siCASP3 siCaspase 3 serum free medium. The virus and cells were incubated at $37^{\circ} \mathrm{C}$ for 4 days. The cytopathic effect of cells was observed using light microscopy. $\mathrm{TCID}_{50}$ was calculated by the Reed-Muench method.

\section{TUNEL assay}

The TUNEL method was performed to label the 3'-end of fragmented DNA of the apoptotic cells. Different cell lines were infected by NDV Herts/33 at an MOI $=1$ and harvested at $20 \mathrm{~h}$ post-infection (h.p.i.), respectively. The TUNEL assay was carried out by Click-iTTM Plus TUNEL Apoptosis Assay Kit according to the manufacture's instruction. The images of TUNEL positive cells were captured by a fluorescence microscope $(\times 200)$.

\section{Flow cytometry}

Various cell lines were infected with NDV Herts/ 33 strain at $\mathrm{MOI}=1$, and harvested at 20 h.p.i. According to the manufacturer's instruction, cells were stained with Annexin V and Propidium Iodide (PI) by using a Dead Cell Apoptosis Kit with Annexin V Alexa Fluor ${ }^{\mathrm{TM}} 488$ \& PI and analyzed with flow cytometry by using flow cytometer (Beckman) equipped with FlowJo software.

\section{Construction of plasmids}

For construction of PXJ40F-CHOP plasmid, full-length CHOP (NM_004083.5) was amplified by PCR from human CDNA using forward primer 5'-CCCAAGCTTA TGGCAGCTGAGTCATTGCCTTTC- $3^{\prime}$ and reverse primer 5'-GGAAGATCTTCATGCTTGGTGCAGATTC ACCATTC- 3 '. The restriction enzyme sites were underlined. The PCR product was digested with Hind III and Bgl II, ligated into vector PXJ40F (with a Flag tag in amino terminus). For construction of pCMV-IRE1 $\alpha$ plasmid, full-length IRE1 $\alpha$ (GenBank: AF059198.1) was amplified by PCR from human cDNA using forward primer $5^{\prime}$ GCAATCAAGCTTATGCCGGCCCGGCGGCTGCTG C-3' and reverse primer 5'-GACGTGGAATTCGAGGG CGTCTGGAGTCACTGGGGGC-3'. The PCR product was digested with Hind $I I I$ and $E c o R I$, ligated into vector p3 4 Flag-CMV-14. For construction of pCMV-XBP1u plasmid, full-length XBP1u (NM_005080.3) was amplified by PCR from human cDNA using XBP1 forward primer $5^{\prime}$-GCAATCAAGCTTATGGTGGTGGTGGCA GCCG-3' and XBP1u reverse primer $5^{\prime}$-GACGTGTCTAGAGTTCATTAATGGCTTCCAGCTTGGC-3'. The PCR product was digested with Hind $I I I$ and $X b a$ $I$, ligated into vector $\mathrm{p} 3 \psi$ Flag-CMV-14. For construction of pCMV-XBP1s plasmid, full-length XBP1s (NM 001079539.1) was amplified by PCR from human cDNA using the forward primer 5'-GCAATCAAGCTTATG GTGGTGGTGGCAGCCG-3' and reverse primer $5^{\prime}$-GA CGTGTCTAGAGACACTAATCAGCTGGGGAAAGA G-3'. The PCR product was digested with the restriction 
enzyme Pst I to remove the XBP1u fragment, followed by Hind III and $\mathrm{Xba} I$ digestion, finally cloned into vector p34Flag-CMV-14.

\section{Transfection of plasmid or siRNA}

HeLa cells were transfected with plasmids or siRNAs using lipofectamine 2000 reagent (Invitrogen, USA) according to the manufacture's manual. At $24 \mathrm{~h}$ (plasmid transfection) or $36 \mathrm{~h}$ (siRNA transfection) post-transfection, cells were incubated with NDV in serum-free medium at $37^{\circ} \mathrm{C}$ for $1 \mathrm{~h}$ to allow the binding and entry. After that, the unbound virus was removed and the cells were incubated with fresh medium (with $2 \%$ FBS). The cells and culture medium were harvested at indicated time, and subjected to western blot analysis, RT-PCR, or $\mathrm{TCID}_{50}$ assay, respectively.

\section{SDS-PAGE and western blot analysis}

Cell lysates were prepared with $2 \times$ SDS loading buffer (20 mM Tis-HCl, pH 8.0, 100 mM Dithiothreitol, 2\% SDS, $20 \%$ Glycerol, and $0.016 \%$ Bromphenol blue) and denatured at $100{ }^{\circ} \mathrm{C}$ for $5 \mathrm{~min}$. The whole cell lysates were separated by SDS-PAGE and transferred onto nitrocellulose membranes (Sigma-Aldrich, USA). The membranes were blocked with $5 \%$ fat free milk in Tris-buffered saline with $0.05 \%$ Tween 20 (TBST) for $1 \mathrm{~h}$, incubated with the primary antibodies (1:1000 in dilution) overnight at $4{ }^{\circ} \mathrm{C}$, then washed thrice with TBST. The membranes were then incubated with secondary antibody (1:1000 in dilution) for $1 \mathrm{~h}$ at room temperature and washed thrice with TBST. The protein bands were detected by enhanced chemiluminescence (ECL) detection system (Share-Bio, Shanghai, China) and exposed to Automatic chemiluminescence image analysis system (Tanon, 5200, China). After the detection, membranes were washed for $5 \mathrm{~min}$ with TBST, followed by rinsing with western blot stripping buffer for $20 \mathrm{~min}$. Then, the membranes were rinsed with TBST and blocked with 5\% fat free milk in TBST before re-probing with other antibodies.

The intensities of target bands were quantified using Image J program (NIH, USA).

\section{Immunofluorescence}

HeLa cells were grown on 6-well chamber slides and infected with NDV. At 16 h.p.i., cells were fixed with $4 \%$ paraformaldehyde for $15 \mathrm{~min}$, permeabilized with $0.5 \%$ Triton X-100 for $10 \mathrm{~min}$, and blocked with 3\% BSA for $30 \mathrm{~min}$. The cells were incubated with antibody against CHOP or XBP1, and NDV NP (1:200 in dilution, 5\% BSA) for $1 \mathrm{~h}$, respectively, followed by staining with secondary antibody conjugating with FITC or TRITC (1:200 in dilution, 5\% BSA) for another $1 \mathrm{~h}$. Finally, cell nuclei were stained with $0.1 \mu \mathrm{g} / \mathrm{ml}$ of DAPI for $10 \mathrm{~min}$ and rinsed with PBS. The specimen was mounted with fluorescent mounting medium (DAKO) containing $15 \mathrm{mM} \mathrm{NaN}$. Images were collected with a LSM880 confocal laserscanning microscope (Zeiss, German).

\section{Quantitative real-time RT-PCR}

Total RNA was extracted using TRIzol ${ }^{\circ}$ Reagent (Invitrogen, USA) according to the manufacturer's instruction. Briefly, cells were lysed with TRIzol and the lysates were mixed with one-fifth volume of chloroform. After centrifugation at $12,000 \times g$ at $4{ }^{\circ} \mathrm{C}$ for $15 \mathrm{~min}$, the aqueous phase was mixed with an equal volume of isopropanol. RNA was pelleted by centrifugation at $12,000 \times g$ at $4{ }^{\circ} \mathrm{C}$ for $20 \mathrm{~min}$, washed with $70 \%$ ethanol twice, and dissolved in RNase-free $\mathrm{H}_{2} \mathrm{O}$. The concentration of the RNA was measured using a NanoDrop 2000 spectrophotometer (Thermo Fisher Scientific, USA).

cDNA was reverse transcribed from total RNA using expand reverse transcriptase (Roche, USA) and oligo-dT primer. Equal volume of cDNA was PCR-amplified using SYBR Green qPCR Mix in a CFX96TM real-time PCR system (Bio-Rad, USA). Primers used for amplification of $\beta$-actin, NP, IRE1 $\alpha$, XBP1u, XBP1s, P58 $8^{\text {IPK }}$ ERdj4, EDEM1, IFN- $\beta$, TNF- $\alpha$, IL6, and IL8 were listed in Table 2. The mRNA levels of specific genes were calculated using $\beta$-actin as an internal reference and normalized to mocktreated controls. All assays were performed in three replicates.

The XBP1 splicing was checked by RT-PCR using forward primer $5^{\prime}$-CCAAGGGGAATGAAGTGAGGC-3' and reverse primer $5^{\prime}$-AGAGTTCATTAAT GGCT TCCAG-3', which produces un-spliced XBP1 of $335 \mathrm{bp}$ and spliced XBP1 of $309 \mathrm{bp}$. The PCR products were digested with the restriction enzyme Pst I, cleaving XBP1u into 72 and $263 \mathrm{bp}$. The digestion products were resolved on $2.5 \%$ agarose gel to separate un-spliced and spliced XBP1.

\section{Statistical analysis}

The statistical analysis was performed with Graphpad Prism5 software (USA). The data were expressed as means \pm standard deviation (SD) of at least three independent experiments. Significance was determined with the one-way analysis of variance (ANOVA). $P$ values $<$ 0.05 were deemed statistically significant.

\section{Densitometry}

The intensities of corresponding bands were quantified using Image J program (NIH) according to the manufacturer's instruction.

\section{Results NDV infection induces apoptosis}

The pathogenesis and oncolytic activity of NDV are associated with cell death. To study whether NDV induces 
Table 2 Primer sequences used for semi-quantitative real-time RT-PCR.

\begin{tabular}{|c|c|}
\hline Name & Sequence $\left(5^{\prime}-3^{\prime}\right)$ \\
\hline$\beta$-actin F & GATCTGGCACCACACCTTCT \\
\hline$\beta$-actin R & GGGGTGTTGAAGGTCTCAAA \\
\hline NP F & CAACAATAGGAGTGGAGTGTCTGA \\
\hline NP R & CAGGGTATCGGTGATGTCTTCT \\
\hline IFN- $\beta$ F & GCTTGGATTCCTACAAAGAAGCA \\
\hline IFN- $\beta$ R & ATAGATGGTCAATGCGGCGTC \\
\hline TNF-a F & AGTGACAAGCCTGTAGCCCC \\
\hline TNF-a R & TTGAAGAGGACCTGGGAGT \\
\hline IL6 F & TGAAAGCAGCAAAGAGGC \\
\hline IL6 R & TCAAATCTGTTCTGGAGGT \\
\hline IL8 F & TCCAAACCTTTCCACCCC \\
\hline IL8 R & CACAACCCTCTGCACCCA \\
\hline IRE1 F & CGGGAGAACATCACTGTCCC \\
\hline IRE1 R & CCCGGTAGTGGTGCTTCTTA \\
\hline XBP1u F & TTGTCACCCCTCCAGAACATC \\
\hline XBP1u R & TCCAGAATGCCCAACAGGAT \\
\hline XBP1s F & TGCTGAGTCCGCAGCAGGTG \\
\hline XBP1s R & GCTGGCAGGCTCTGGGGAAG \\
\hline P58IPK F & GGCTCGGTATTCCCCTTCCT \\
\hline P58IPK R & AGTAGCCCTCCGATAATAAGCAA \\
\hline ERdj4 F & TGTCAGGGTGGTACTTCATGG \\
\hline ERdj4 R & TCTTAGGTGTGCCAAAATCGG \\
\hline EDEM1 F & CGGACGAGTACGAGAAGCG \\
\hline EDEM1 R & CGTAGCCAAAGACGAACATGC \\
\hline
\end{tabular}

$F$ represents forward primer, $R$ represents reverse primer

apoptosis in host cells and human cancer cells, chicken cells CEF and DF-1, human cancer cells HeLa, Cal27, HN13, A549, H1299, Huh7, and HepG2, were infected with Herts/33, a virulent strain of NDV. These infected cells were then subjected to apoptosis analysis. The noncancerous human embryonic kidney cells, 293T, were infected as a control cell type. Due to space limitations, we presented the results from HeLa cells in Figs. 1-8 and the results for other cell lines in supplementary figures. As expected, at 20 h.p.i., increased number of TUNEL positive cells was observed in HeLa (Fig. 1a), as well as in CEF, DF-1, Cal27, HN13, A549, H1299, Huh7, and HepG2 cells (Fig. S1A); only few TUNEL positive cells were observed in 293T cells (Fig. S1A). Annexin V/PI staining confirmed that NDV indeed induced functional apoptosis in chicken and human cancer cells, but not in 293T cells (Fig. 1b, Fig. S1B). Immunoblotting showed that in HeLa, Cal27,
HN13, A549, and H1299 cells, both major biochemical markers of apoptosis, caspase- 3 and PARP, were cleaved into smaller fragments in an infection time-dependent manner; in Huh7 and HepG2 cells, weak cleavage of PARP appeared at 24 h.p.i.; no cleavage of both biochemical markers was observed in 293T cells (Fig. 1c and Fig. S1C). Due to unavailabilbty antibodies, chicken cells were not included in the immunoblotting analysis. These observations suggest that NDV infection triggers functional apoptosis in chicken cells and many human cancer cell types, but not in non-cancerous $293 \mathrm{~T}$ cells.

To investigate the role of apoptosis in NDV proliferation, we utilized siRNA to specifically knockdown caspase-3. As shown in Fig. 1d, caspase-3 was successfully knocked down, accompanying with decreased cleavage of PARP. Interestingly, the expression of viral NP was also reduced at late infection time points. Examination of extracellular virus titer showed that knock down of caspase-3 significantly suppressed the production of progeny virus (Fig. 1e). These results suggest that apoptosis promotes virus proliferation, probably by facilitating virus release and spread.

\section{NDV infection activates the three branches of UPR signaling}

We next set up to adress if the UPR is involved in NDVinduced apoptosis. First, we examined the three branches of UPR in NDV-infected cells. As shown in Fig. 2a and Fig. S2, at late infection time points. Interestingly, the fulllength PERK (PERK-FL) was cleaved into a $110-\mathrm{kDa} \mathrm{N}$ terminal fragment (PERK-N) in HeLa, Cal27, HN13, A549, and H1299, but not in Huh7, HepG2, and $293 \mathrm{~T}$ cells. The cleavage site of PERK was mapped to Thr980 (data not shown). In the mock-infected group, there was basal level of phospho-PERK, probably due to the removal of serum in the culture medium (Fig. 2a and Fig. S2). The phospho-PERK was clear observed in NDVinfected Hela cells at 16 and 20 h.p.i. (Fig. 2a), however, in other cancer cell lines, the level of phospho-PERK in NDV-infected cells was lower than or comparable to that in mock-infected cells, probably due to the cleavage of PERK-FL or other unknown mechanisms (Fig. S2). Meanwhile, phospho-eIF2 $\alpha$ was gradually increased at late infection time points in HeLa cells (Fig. 2a), and in HN13, A549, Huh7, HepG2, and 293T cells (Fig. S2). The failure to observe the increase of phospho-eIF $2 \alpha$ in NDVinfected Cal27 and H1299 cells might be attributed to the high basal level of phospho-eIF $2 \alpha$ in mock-infected cells. These results demonstrate that NDV infection induces the phosphorylation of eIF $2 \alpha$ in various cancer cells; however, the cleavage of PERK may attenuate the activation of PERK-eIF2 $\alpha$ branch. Meanwhile, NDV infection greatly stimulated the phosphorylation of IRE1 $\alpha$ in HeLa (Fig. 2a), Cal27, HN13, A549, H1299, Huh7, and HepG2 


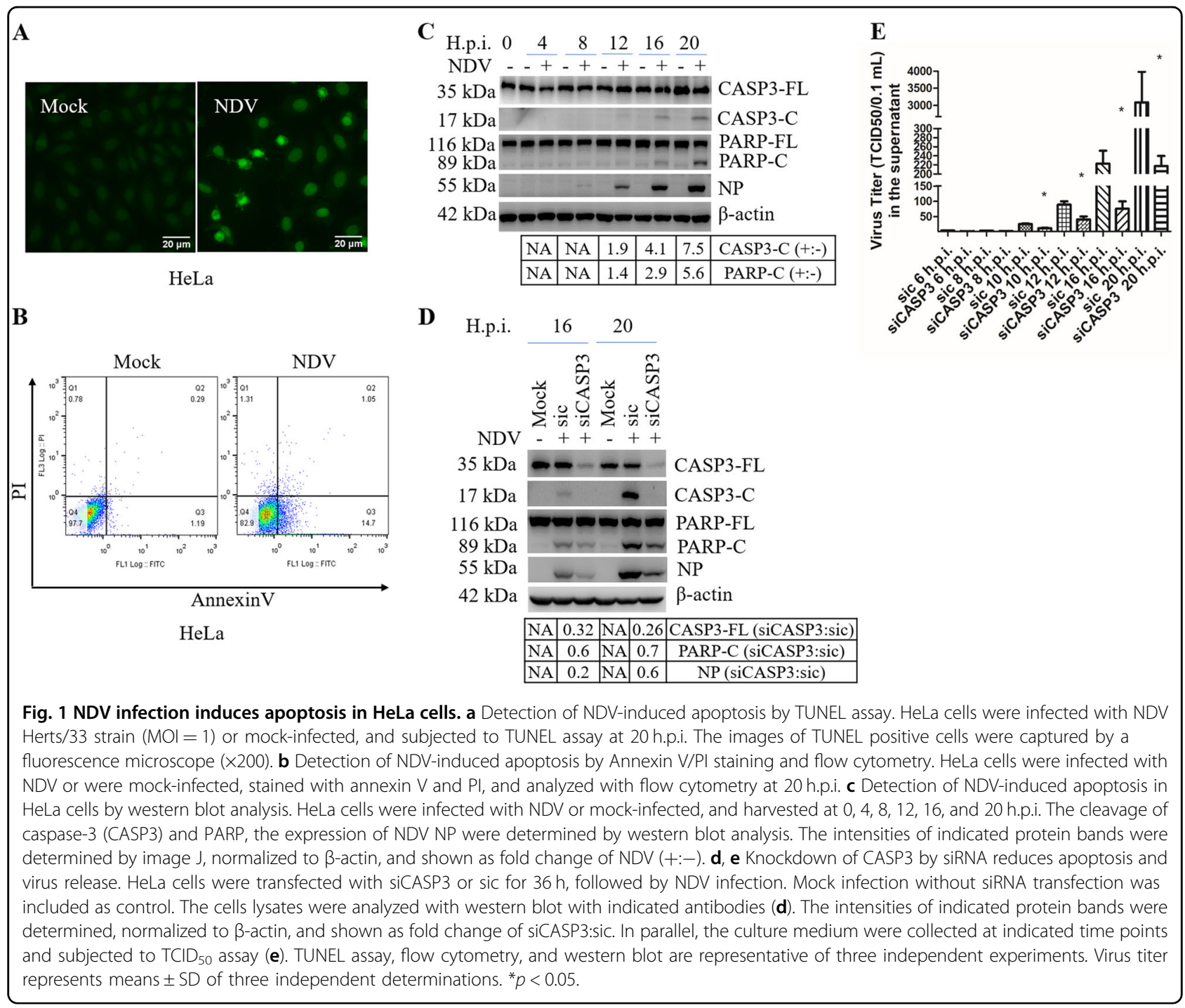

cells, but not in 293T cells (Fig. S2). The level of full-length ATF6 (ATF6-FL) was gradually decreased at late infection time in HeLa (Fig. 2a), Cal27, A549, H1299, Huh7, and 293T, but not in HN13 and HepG2 (Fig. S2). Although we failed to detect the cleavage band of ATF6, the nuclear translocation of ATF6 was indeed observed in NDVinfected HeLa cells (Fig. 2b). These results demonstrate that NDV infection triggers the eIF2 $\alpha$, IRE $1 \alpha$, and ATF6 signaling in most cancer cell types studies.

We next evaluated the role of UPR in apoptosis and virus proliferation, by utilizing a chemical chaperone 4PBA to attenuate ER stress ${ }^{39}$. In HeLa cells receiving both 4-PBA and NDV, the level of phospho-eIF2 $\alpha$ was reduced by 0.7 -fold; interestingly, both phospho-IRE1 $\alpha$ and total IRE1 $\alpha$ were increased, whereas the cleavage of ATF6-FL was not affected, compared to those cells receiving NDV only (Fig. 2c). Thus, 4-PBA only suppressed the phosphorylation of eIF2 $\alpha$ in NDV-infected cells. Further study showed that 4-PBA treatment decreased the cleavage of PARP and produced less TUNNEL positive cells (Fig. 2c, d), accompany with lower expression of NP and less release of progeny virus (Fig. 2e). Thus, alleviation of eIF2 $\alpha$ phosphorylation by 4-PBA may protect cells from death and is not favorable for virus proliferation.

\section{NDV infection induces the expression of CHOP via PERK and PKR signaling}

Under prolonged ER stress, the preferentially translation of ATF4 usually promotes the expression of pro-apoptotic transcription factor $\mathrm{CHOP}^{40,41}$. Here, we found that the expression of $\mathrm{CHOP}$ was significantly induced at late infection time in all cell types (Fig. 3a, Fig. S3A). Immunofluorescence showed that strong $\mathrm{CHOP}$ signal was mainly localized in the nucleus at 16 h.p.i. (Fig. 3b). Thus, the persistent exposure to NDV infection greatly induces the expression and nuclear translocation of $\mathrm{CHOP}$. 


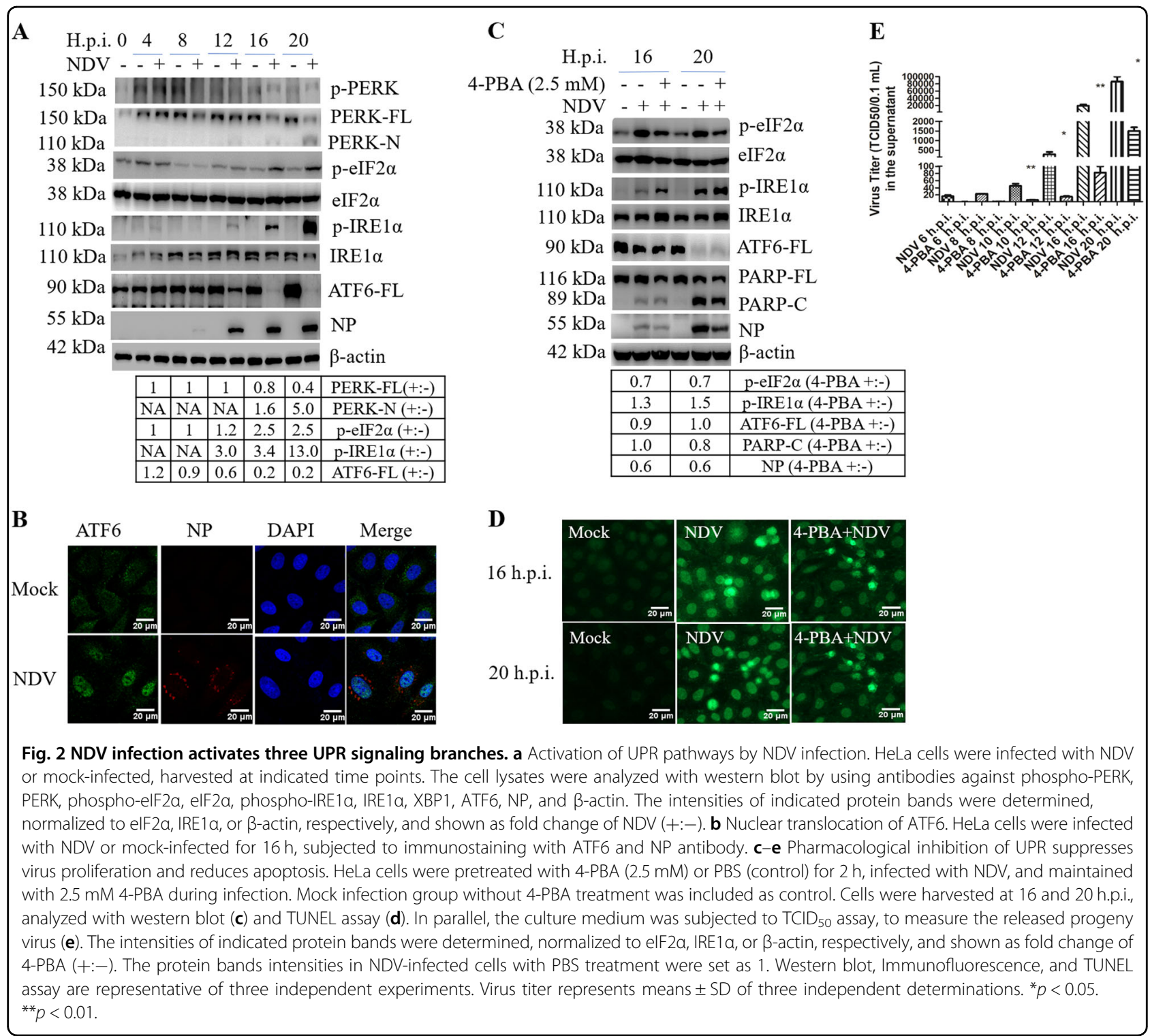

To clarify whether PERK-eIF2 $\alpha$ or PKR-eIF2 $\alpha$ signaling is involved in CHOP induction, we specifically knocked down PERK and PKR, respectively. Results showed that knock down of either PKR or PERK decreased the level of phospho-eIF2 $\alpha$ and reduced the expression of CHOP at both mRNA and protein level (Fig. 3c). Pharmacological inhibition of PERK and PKR by $10 \mu \mathrm{M}$ GSK2606414 confirmed above results (Fig. S3B). Thus, both PERK and PKR contribute to the phosphorylation of eIF2 $\alpha$ and transcriptional induction of CHOP during NDV infection.

\section{CHOP promotes apoptosis by reducing the level of anti- apoptotic protein BCL-2 /MCL-1}

Is CHOP involved in NDV-induced intrinsic apoptosis? It has been known that $\mathrm{CHOP}$ promotes mitochondria mediated apoptosis via downregulation of the pro-survival
BCL-2 ${ }^{24,42}$. First, we examined the levels of BCL-2 family members during NDV infection. As shown in Fig. 4a, prosurvival guardian protein $\mathrm{BCL}-2$ and $\mathrm{MCL}-1$ were gradually decreased from 16 to 20 h.p.i., while BCL-xL remained relatively stable; the pro-apoptotic BIM and PUMA, the pore forming protein BAX, were slightly decreased at 16 and 20 h.p.i., and the pore forming protein BAK was kept at a steady level. The decrease of BCL-2/ MCL-1 may allow BAX/BAK to form pores in the outer membranes of mitochondria.

To investigate whether $\mathrm{CHOP}$ is involved in regulating the levels of BCL-2 and MCL-1, we specifically knocked down the expression of CHOP, followed with NDV infection. As shown in Fig. 4b, accompanying with depletion of CHOP, the levels of MCL-1 and BCL-2 were recovered, and the cleavage of PARP was reduced; 
A

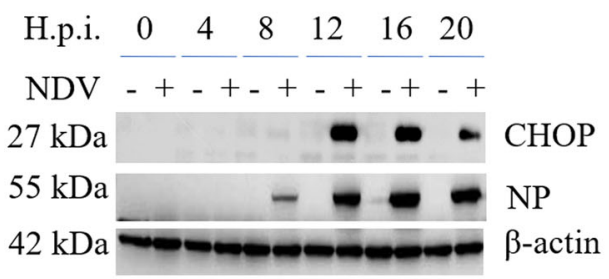

B

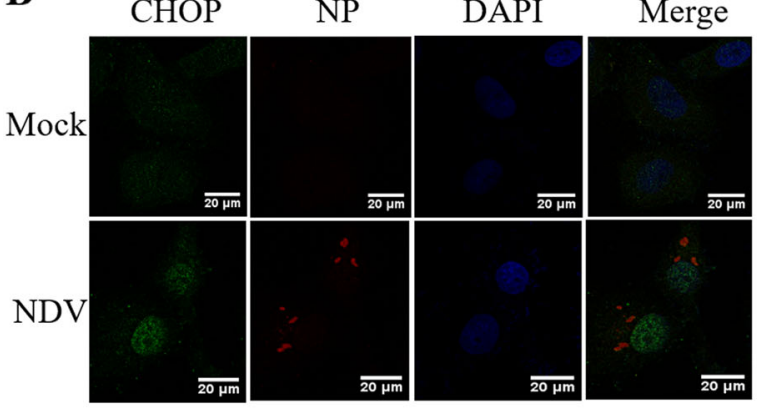

C

$150 \mathrm{kDa}$

$110 \mathrm{kDa} \_$PERK-N

$74 \mathrm{kDa}=\mathrm{p}-\mathrm{PKR}$

$74 \mathrm{kDa}=-\mathrm{PKR}$

$38 \mathrm{kDa} \ldots \ldots$ p-eIF2 $\alpha$

$38 \mathrm{kDa}-\mathrm{eIF} 2 \alpha$

$27 \mathrm{kDa}-\mathrm{m}-\mathrm{CHOP}$

$55 \mathrm{kDa}=\mathrm{NP}$

$42 \mathrm{kDa}=\beta$-actin

\begin{tabular}{|c|c|c|c|}
\hline 1 & 1.0 & 0.2 & PERK (siTarget:sic) \\
\hline 1 & 0.1 & 1.0 & PKR (siTarget:sic) \\
\hline 1 & 0.4 & 0.4 & p-eIF2 $\alpha$ (siTarget:sic) \\
\hline 1 & 0.7 & 0.5 & CHOP (siTarget:sic) \\
\hline
\end{tabular}

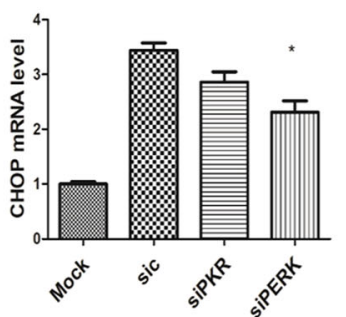

Fig. 3 NDV infection induces the expression of pro-apoptotic transcription factor CHOP. a Induction of CHOP by NDV infection. HeLa cells were infected with NDV and harvested at indicated time points. The cell lysates were analyzed by western blot with antibodies against CHOP and NP. $\beta$-actin was detected as a loading control. b Nuclear translocation of CHOP during NDV infection. HeLa cells were infected with NDV or mockinfected for $16 \mathrm{~h}$, subjected to immunostaining by using antibodies against CHOP and NP. The signal of CHOP (green) and viral protein NP (red) were observed under confocal microscope. $\mathbf{c}$ Knockdown of PKR or PERK reduces the phospho-elF2a and expression of CHOP. HeLa cells were transfected with sic, siPERK, or siPKR, before infecting with NDV. Mock infection was set as control. At 20 h.p.i., cell samples were analyzed by western blot (upper panel) and quantitative real-time RT-PCR (low panel). The intensities of indicated protein bands were normalized to elF2a or $\beta$-actin, respectively, and shown as fold change of siTarget:sic. Western blot and Immunofluorescence are representative of three independent experiments. CHOP mRNA level represents means \pm SD of three independent determinations. ${ }^{*} p<0.05,{ }^{* *} p<0.001$.

interestingly, significant decrease of the expression of NP and the release of progeny virus were observed. To further demonstrate above observation, we adopted the transient overexpression approach. As shown in Fig. 4c, compared with vector-transfected group, overexpression of $\mathrm{CHOP}$ greatly reduced the levels of MCL-1 and BCL-2, resulting in higher level of PARP cleavage; the level of viral protein $\mathrm{NP}$ and the release of progeny virus were greatly increased. These data confirm that induction of $\mathrm{CHOP}$ promotes apoptosis via downregulating BCL-2/MCL-1 and supports NDV proliferation.

\section{CHOP promotes apoptosis by regulating AKT and JNK signaling cascades}

AKT plays a critical role in promoting cell survival ${ }^{43}$. MAPK cascades are involved in cell growth, differentiation, and control of cellular responses to cytokines and stress $^{44,45}$. To investigate whether AKT and MAPK signaling are involved in NDV-induced apoptosis, the kinetic activation of these kinases was examined. As shown in Fig. 5a, although there were basal levels of phospho-AKT and phospho-ERK1/2 after the serum was removed from culture medium during infection, the levels of both phospho-AKT and phospho-ERK1/2 were increased at late infection time; meanwhile, a gradual increase of phospho-JNK and phospho-p38 were clearly detected. These observations reveal that NDV infection activates AKT and three branches of MAPK signaling.

To study whether CHOP is involved in regulating AKT and MAPK signaling, we examined the phosphorylation levels of these kinases by knock down or overexpression of CHOP. As shown in Fig. 5b, depletion of CHOP indeed decreased the levels of phospho-JNK, phospho-p38, and phospho-ERK $1 / 2$ by 0.6 - to 0.7 -fold, respectively, although the level of phospho-AKT was not changed. In contrast, overexpression of $\mathrm{CHOP}$ reduced the level of 


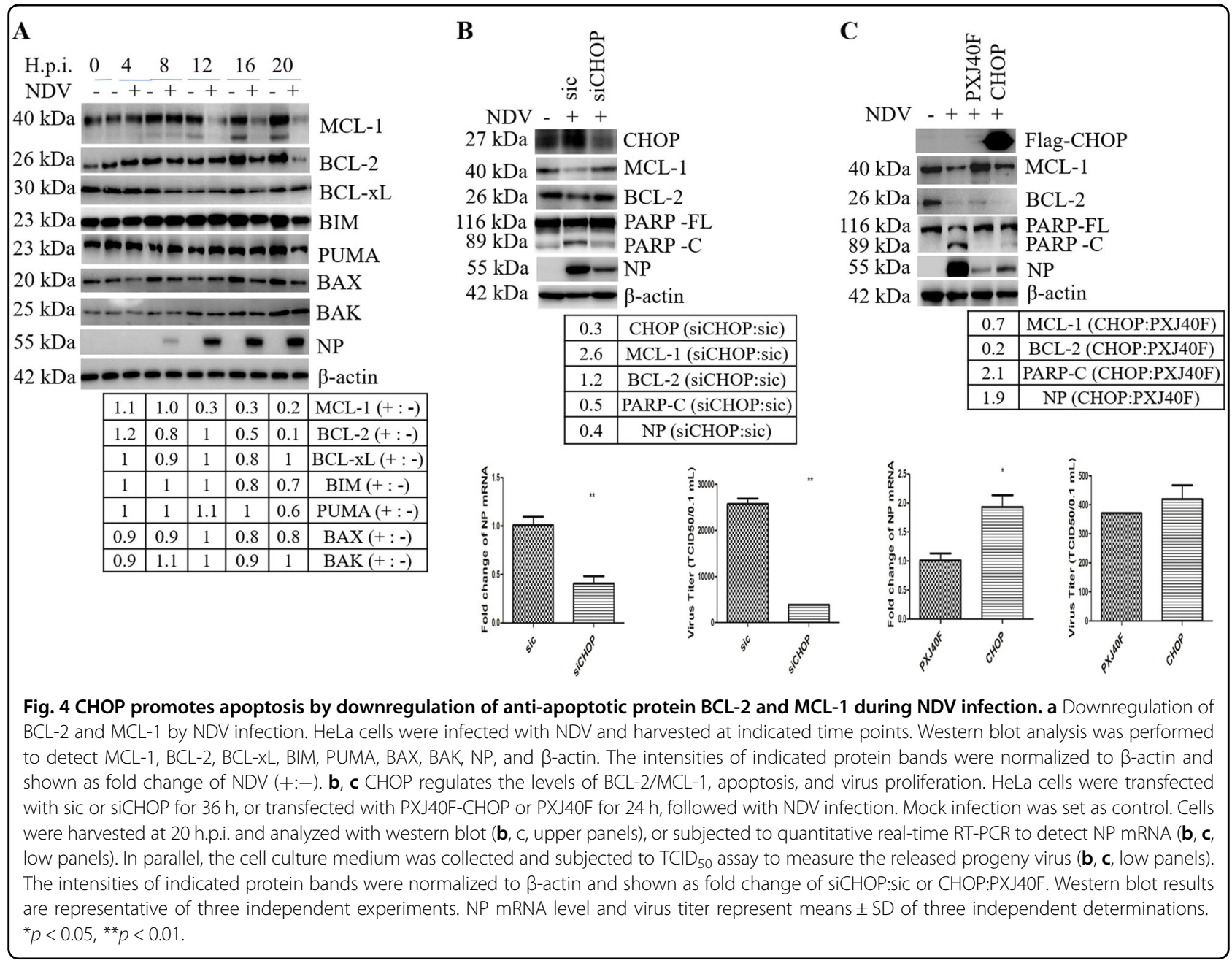

phospho-AKT by 0.6 -fold and greatly stimulated phosphorylation of JNK by 4.6-fold, phosphorylation of p38 and ERK1/2 by 1.2 -fold (Fig. 5c). From these data, we speculate that $\mathrm{CHOP}$ may promote apoptosis by suppressing AKT signaling and enhancing MAPK signaling.

To evaluate the effect of AKT and MAPK signaling on apoptosis, we employed siRNA to specifically interfere the expression of AKT, JNK, p38, or ERK1/2. As shown in Fig. $5 \mathrm{~d}$, knock down of AKT obviously increased the cleavage of PARP; knocking down of JNK slightly decreased the cleavage of PARP; depletion of p38 and ERK1/2 did not significantly change the cleavage of PARP. These observations were further confirmed by pharmacological inhibition of AKT, JNK, p38, and ERK1/2, respectively (Fig. S4A-D). Thus, AKT and JNK are the major pathways involved in apoptosis during NDV infection.

\section{IRE1 a mediated-XBP1 splicing is essential for efficient NDV proliferation and apoptosis}

We have observed the activation of IRE1 $\alpha$ in Fig. 2 and Fig. S2, next, we examined the splicing of XBP1. As shown in Fig. 6, the splicing form of XBP1s mRNA was clearly detected at 12-20 h.p.i. (Fig. 6a), meanwhile, the $55 \mathrm{kDa}$ XBP1s protein was observed (Fig. 6b). The expression of XBP1s was also detected in NDV-infected Cal27, HN12, A549, H1299, Huh7, HepG2, and 293T cells (Fig. S2). Immunofluorescence showed that XBP1 was translocated to the nucleus in response to NDV infection (Fig. 6c). These results clearly demonstrate that NDV infection triggers XBP1s mRNA splicing and produces XBP1s as a nuclear transcription factor.

We next examined the effect of IRE1 $\alpha$ on XBP1 splicing. IRE1 $\alpha$ ribonuclease activity was inhibited by $4 \mu 8 \mathrm{c}$, which specifically binds to the lysine residue in the catalytic pocket. Results in Fig. 6d showed that $25 \mu \mathrm{M} 4 \mu 8 \mathrm{c}$ treatment markedly suppressed NDV-induced splicing of XBP1 mRNA. To eliminate the possibility of off target by chemical treatment, we specifically knocked down or overexpressed IRE1 $\alpha$. Compared with control group, knock down of IRE1 $\alpha$ reduced the level of XBP1s to undetectable level (Fig. 6e); in contrast, overexpression of IRE1 $\alpha$ produced 2-fold of XBP1s (Fig. 6f). Collectively, 


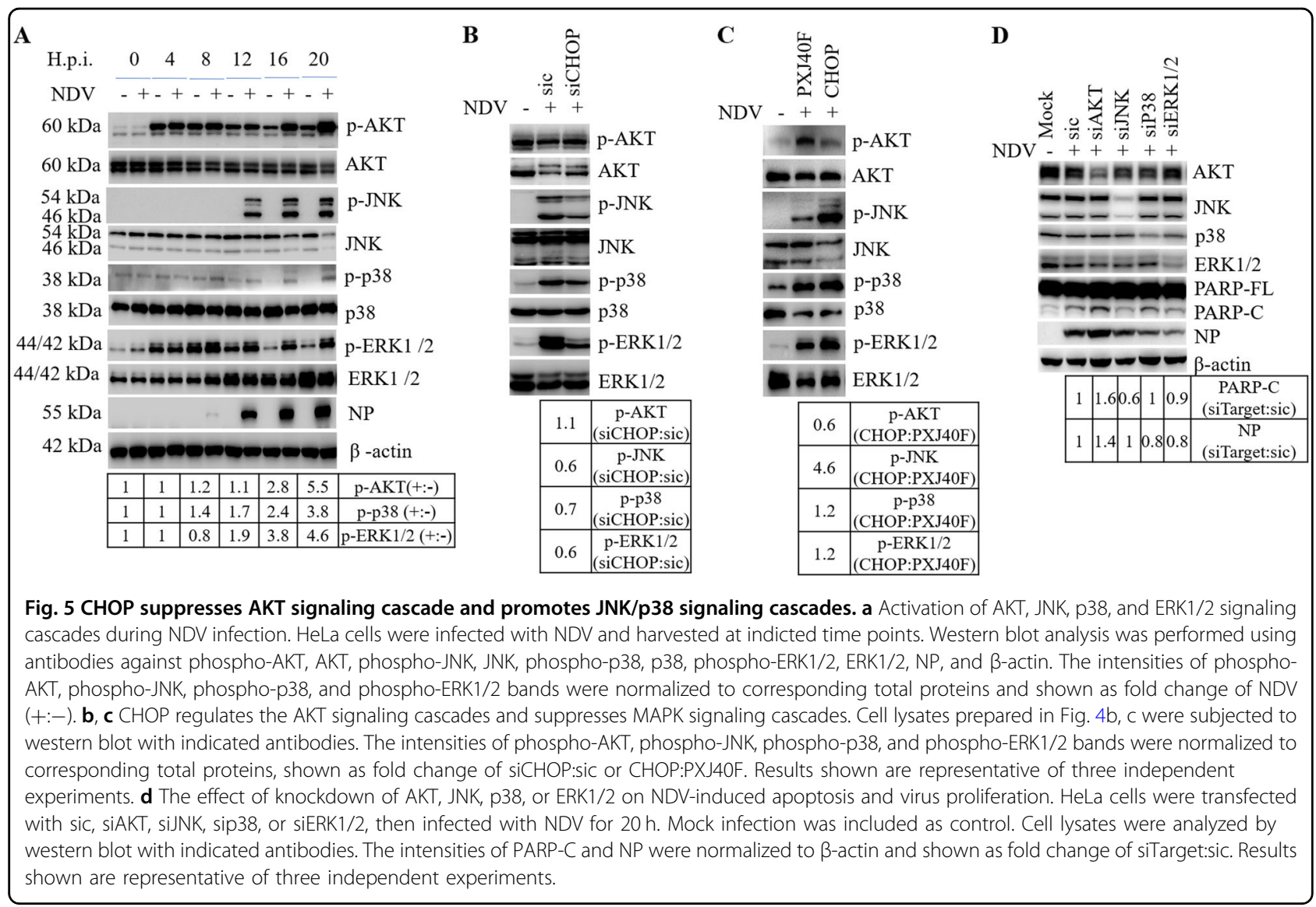

these results confirm that IRE1 $\alpha$ ribonuclease is responsible for the splicing of XBP1 mRNA and production of $\mathrm{XBP} 1 \mathrm{~s}$ in response to NDV infection.

\section{IRE1a-XBP1 promotes NDV-induced apoptosis and facilitates viral proliferation}

IRE1 $\alpha$ has shown to be involved in cell death under prolonged/severe ER stress ${ }^{25,46}$. To assess the role of IRE $1 \alpha$ on cell fate during NDV infection, IRE1 $\alpha$ was knocked down. As shown in Fig. 7a, compared to those in sic-transfected cells, knock down of IRE1 $\alpha$ reduced the cleavage of caspase- 3 and PARP, impaired the expression of NP and the production of progeny virus. Meanwhile, the transcriptional induction of the ER chaperones and components of ERAD, including $\mathrm{p} 58^{\mathrm{IPK}}$, ERdj4, and EDEM1 genes, was reduced in IRE1 $\alpha$ knock down cells (Fig. S5A). We further analyzed this observation by overexpression of IRE1 $\alpha$. As shown in Fig. 7b, compared with vector pCMV trasfected cells, overexpression of IRE1 $\alpha$ promoted the phosphorylation of IRE1 $\alpha$, enhanced the cleavage of caspase- 3 and PARP, and increased the expression of NP and production of progeny virus. As expected, the transcription of the ER chaperones and ERAD components was increased (Fig. S5B).
To study the role of XBP1 in NDV-induced apoptosis, HeLa cells were transfected with Flag-tagged XBP1u, $\mathrm{XBP} 1 \mathrm{~s}$, and $\mathrm{pCMV}$ vector. Neither XBP1u nor XBP1s changed the cleavage of PARP and the synthesis of NP (Fig. 7c). However, knock down of XBP1 reduced the cleavage of PARP and suppressed virus proliferation, as evidenced by the decrease of NP synthesis, viral mRNA transcription, and progeny virus production (Fig. 7d). These results demonstrate that IRE1 $\alpha$-XBP1 triggers the transcription of ER chaperones/ERAD components, promotes apoptosis, and supports efficient NDV replication.

\section{JNK signaling is activated via IRE1a/NF-KB signaling and is} involved in NDV-induced apoptosis/inflammation

We next asked whether IRE1 $\alpha$ is involved in JNK activation. Interfering the expression of IRE1 $\alpha$ by siRNA reduced the level of phospho-JNK by 0.2 -fold (Fig. 8a); in contrast, in cells transfected with plasmid encoding IRE1 $\alpha$, the level of phospho-JNK was markedly increased by 2.2 -fold (Fig. 8 b). These data demonstrate that IRE1 $\alpha$ promotes JNK phosphorylation in NDV-infected cells. Previously, we reported that NDV infection-induced death ligand TNF- $\alpha$ expression via NF- $\mathrm{B}$ pathway ${ }^{37}$. Usually, the binding of TNF- $\alpha$ to TNFR not only activates 


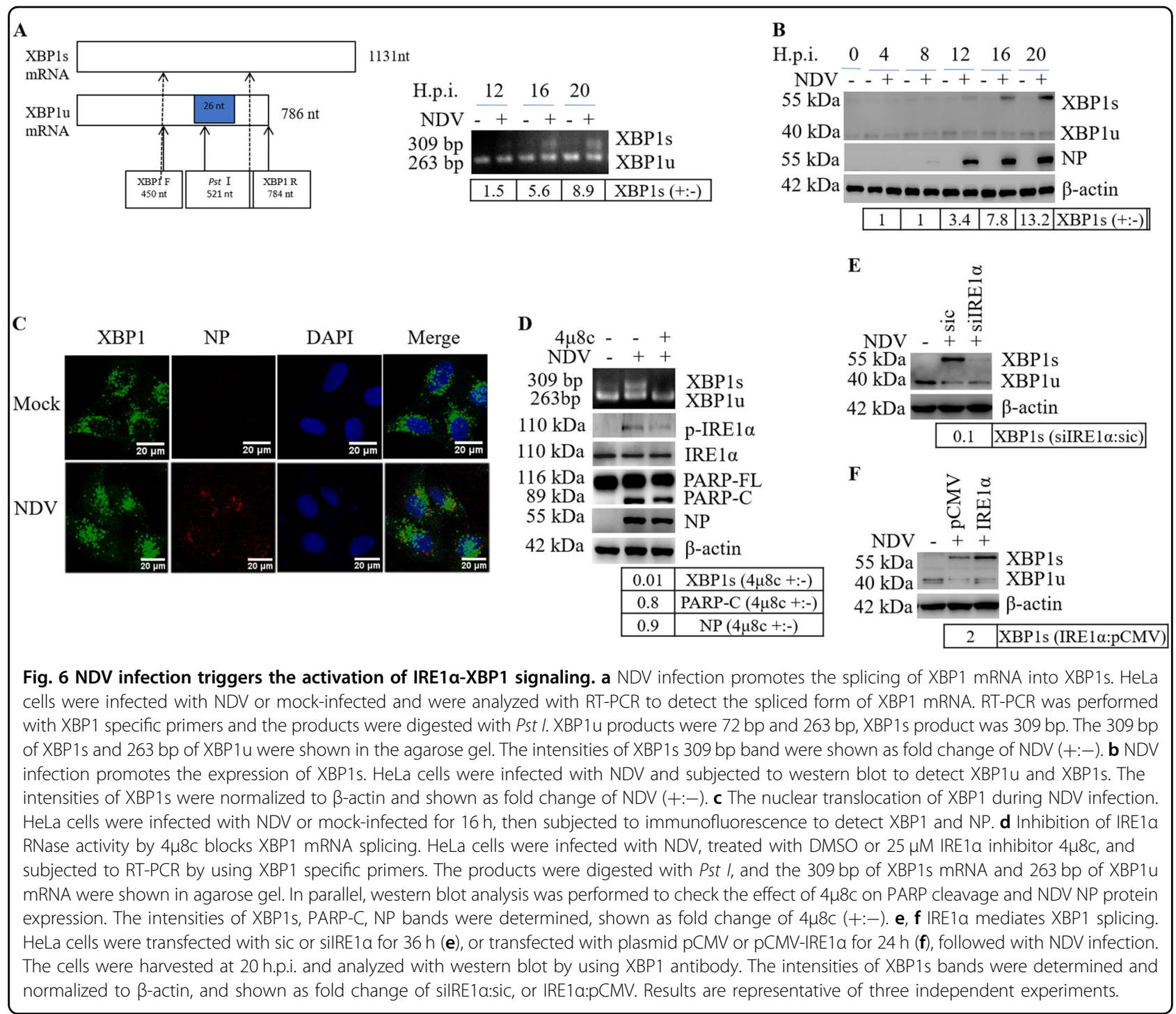

caspase 8 and NF- $\mathrm{KB}$, but also triggers JNK ${ }^{47}$. To examine whether NF- $\mathrm{KB}$ signaling is involved in the activation of JNK, IKK $\beta$ inhibitor IKK16 $(5 \mu \mathrm{M})$ was incubated with $\mathrm{NDV}$-infected cells to block the activation of NF- $\mathrm{KB}$. As shown in Fig. 8c, inhibition of NF- $\mathrm{kB}$ signaling reduced the level of phospho-JNK to undetectable level, demonstrating that JNK is also activated via the NF- $\mathrm{KB}$ pathway.

JNK promotes apoptosis as well as inflammation ${ }^{48}$. Is the activation of JNK involved in the transcriptional induction of cytokines? Here, we used SP600125 to inhibit JNK kinase activity, or specifically interfered the expression of JNK by siRNA, then evaluated IRF3 and NF- $\mathrm{kB}$ signaling. Results in Fig. 8d, e showed that both inhibition and knocking down of JNK reduced the levels of phosphoTBK1, phospho-IRF3 and phospho-p65; surprisingly, virus proliferation was also suppressed. Accordingly, the transcription of TNF- $\alpha$, IL6, and IL8 was markedly suppressed; the transcription of IFN- $\beta$ was significantly suppressed by the inhibitor treatment, but only slightly decreased in JNK knock down cells (Fig. S5A, B). Collectively, these results demonstrate that JNK promotes cytokines transcription during NDV infection, probably via regulation of $\mathrm{NF}-\mathrm{kB}$ and IRF3 signaling. It was worthwhile to note that the release of progeny virus was greatly suppressed by inhibition of JNK, suggesting that JNK signaling is helpful for virus proliferation.

\section{Discussion}

As an acute infection pathogen and oncolytic reagent, NDV specifically kills host cells and tumor cells by inducing apoptosis and inflammation. In this study, we demonstrate that NDV infection initiates the UPR signaling and triggers functional apoptosis in chicken cells as well as in various cancer cell types; suppression of either 


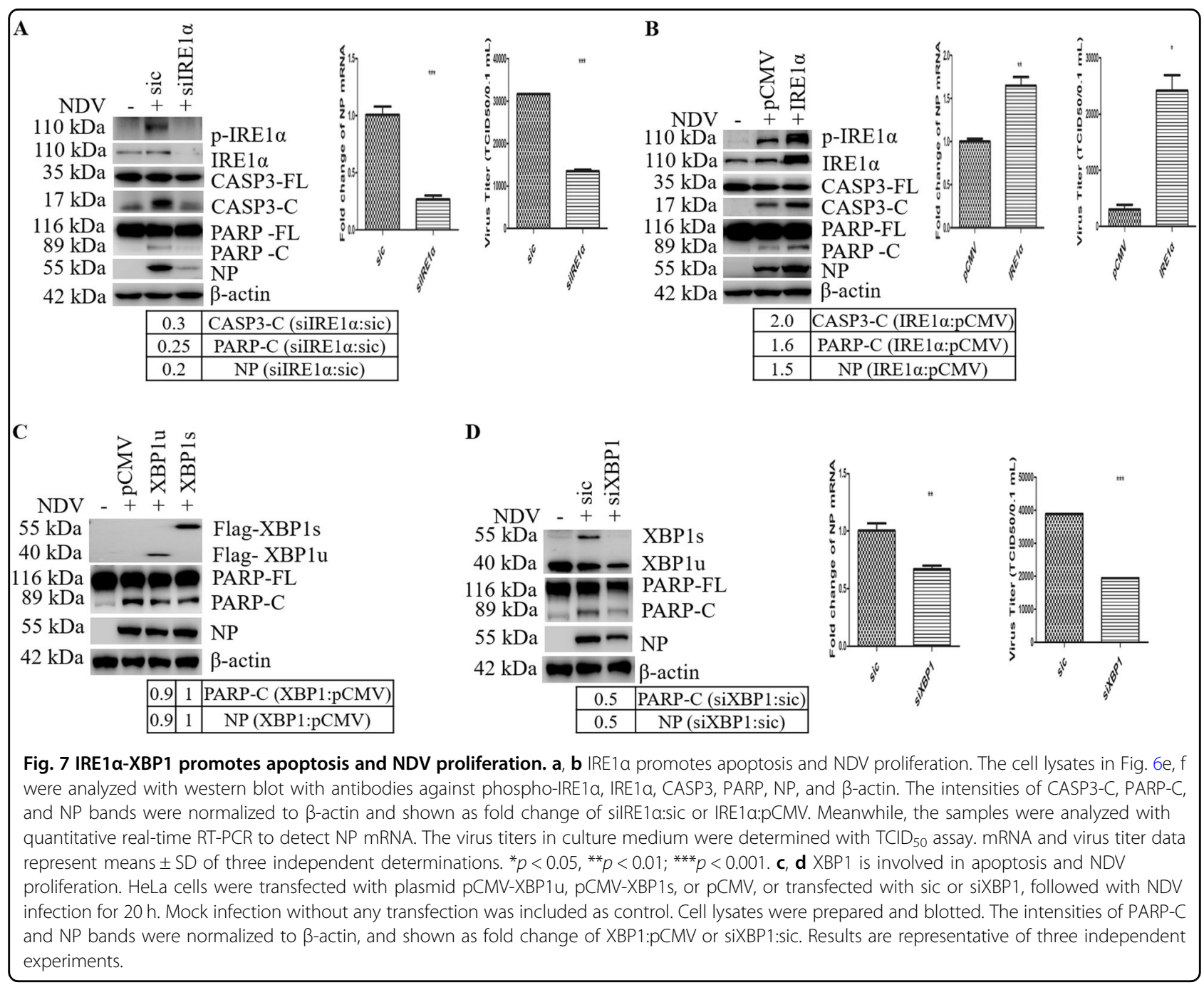

UPR or apoptosis is not favorable for efficient NDV proliferation. Indeed, to facilitate shedding and dissemination of progeny viruses, some viruses take advantage by initiating apoptosis ${ }^{49}$. Apoptosis may help NDV release by killing the infected cells, promote virus spread to neighbor cells by avoiding stimulation of anti-viral innate immune responses or inflammation in un-infected neighbor cells, thereby quickly establishing acute infection.

UPR determines cell fate to survival or death ${ }^{50,51}$. Here, we find that the UPR is involved in NDV-induced apoptosis by triggering the expression of CHOP via PERK/ PKR-eIF2 $\alpha$ dependent manner. The mechanisms of $\mathrm{CHOP}$ to promote apoptosis include decreasing the levels of BCL-2 and MCL-1, which may result in release of BAX to form pores in mitochondria outer membranes ${ }^{52}$; limiting the activation of pro-survival AKT; and promoting the signaling of pro-apoptotic $\mathrm{JNK}^{53,54}$. Activation of $\mathrm{p} 38$ during NDV infection may also lead to phosphorylation and activation of $\mathrm{CHOP}^{55,56}$. Interestingly, induction of CHOP supports efficient NDV proliferation.
IRE1 $\alpha$ is a highly conserved ER stress sensor, which is involved in determination of cell fate ${ }^{57}$. Viruses have different mechanisms to regulate IRE1 $\alpha$ signaling, to facilitate their own replication. Hepatitis B virus, Influenza A virus, Japanese encephalitis virus, and Flavivirus activate IRE1-XBP1 singaling ${ }^{58-61}$, while Hepatitis $C$ virus and Rotavirus suppress this pathway ${ }^{62,63}$. In this study, we demonstrate that NDV infection activates IRE1 $\alpha-\mathrm{XBP} 1$ and IRE1 $\alpha-J N K$ signaling, leading to sensitizing cells to apoptosis and enhancing NDV proliferation. JNK also promotes the expression of pro-inflammatory cytokines. The activation of JNK is not only modulated by CHOP and IRE1 $\alpha$, but also triggered by NF- $\mathrm{kB}$ signaling. Thus, JNK plays an essential role in the crosstalk of UPR, apoptosis, and inflammation during NDV infection.

The principal findings of this study are NDV infection promotes apoptosis and inflammation in various cancer cell types via UPR, including the eIF $2 \alpha-\mathrm{CHOP}-\mathrm{BCL}-2 /$ JNK signaling and IRE1 $\alpha-\mathrm{XBP} 1 \mathrm{~s} / \mathrm{JNK}$ signaling, which is helpful for NDV proliferation (summarized in Fig. S7). 
A

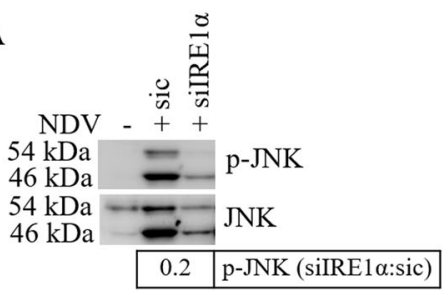

D

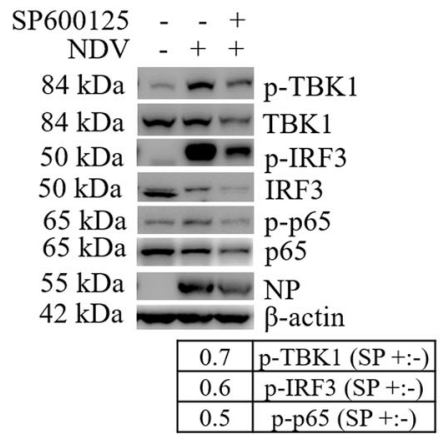

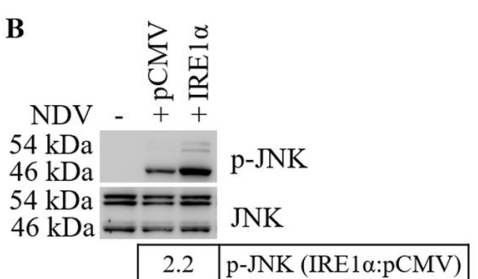

C
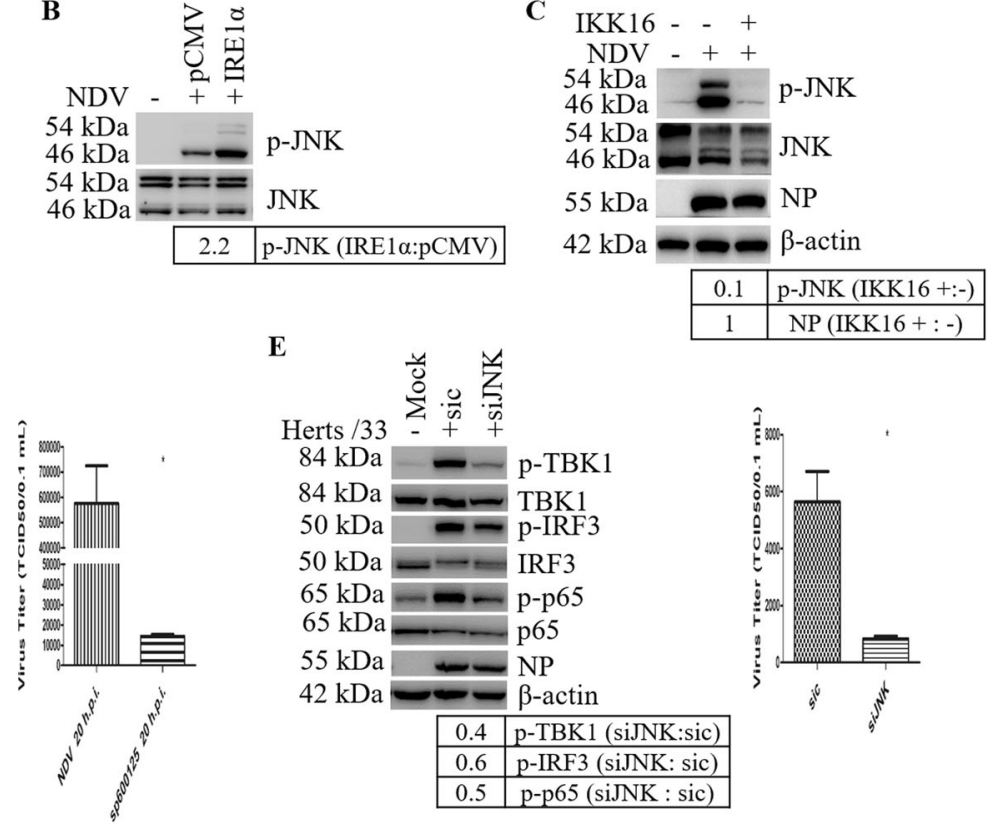

$\mathbf{E}$

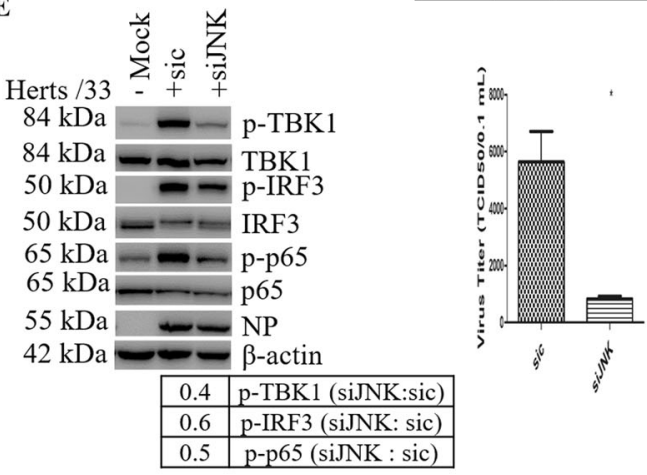

Fig. 8 NDV infection activates pro-apoptotic and pro-inflammatory JNK signaling cascade via IRE1a and NF-KB pathway. a, b IRE1a promotes JNK signaling. Cell samples in Fig. 6e, f were analyzed with western blot to check the phospho-JNK and JNK. The intensities of phospho-JNK bands were normalized to total JNK, shown as fold change of silRE1a:sic or IRE1 a:pCMV. c Pharmacologic inhibition of NF-KB signaling suppresses JNK activation. HeLa cells were infected with NDV, followed by incubation with DMSO or $5 \mu$ M IKK16. At 20 h.p.i., the levels of phospho-JNK, JNK, NP, and $\beta$-actin were analyzed with western blot. The intensities of phospho-JNK and NP bands were normalized to total JNK or $\beta$-actin, shown as fold change of IKK16 (+:-). d, e Inhibition of JNK suppresses IRF3 and NF-KB signaling and reduces virus proliferation. HeLa cells were infected with NDV, followed by treatment with DMSO or $7.5 \mu \mathrm{M}$ JNK inhibitor SP600125, and harvested at 20 h.p.i. (d). In parallel, HeLa cells were transfected with siJNK or sic for $48 \mathrm{~h}$, followed by NDV infection for $20 \mathrm{~h}$ (e). Mock infection was included as control. The protein level of phospho-TBK1, TBK1, phospho-IRF3, IRF3, phospho-p65, p65, NP, and $\beta$-actin were analyzed with western blot. The intensities of phospho-TBK1, phospho-IRF3 and phospho-p65 bands were normalized to total TBK1, IRF3, p65, shown as fold change of SP600125 (+:-) or siJNK:sic. Western blot shown are representative of three independent experiments. Meanwhile, the cell culture supernatants were collected and subjected to $\mathrm{TCID}_{50}$ assay. Virus titer represent means $\pm \mathrm{SD}$ of three independent determinations. ${ }^{*} p<0.05$.

The full understanding of the involvement of these UPR branches in NDV replication process appears to be complicated. In addition to helping NDV spread to neighbor cells by triggering apoptosis, the global translation shut off caused by PERK/PKR-eIF2 $\alpha$ signaling may allow the translational machinery hacked by virus and translate the viral proteins preferentially. Alternatively, the expression of ER quality control proteins, which are controlled by IRE1 $\alpha$-XBP1 pathway, promotes virus replication by enhancing the viral proteins modification, folding, and trafficking. Another possibility is that XBP1s stimulates the phospholipid biosynthesis and ER expansion ${ }^{64}$, providing the lipid that is necessary for the enveloped virus particle assembly. Activation of JNK by UPR not only contributes to apoptosis, but also initiates inflammation by promoting the transcription of cytokines. The secretion of cytokines may attract the phagocyte to engulf the infected-apoptotic cells. In all, this study provides comprehensive insights into the mechanisms of UPR induced apoptosis and cytokinesecretion during NDV infection.

\section{Acknowledgements}

This work was supported by National Natural Science foundation of China (Grant No. 31772724), Natural Science foundation of Shanghai (Grant No. 15ZR1449600), National Key Research and Development Program (Grant No. 2017YFD0500802), Elite Youth Program of Chinese Academy of Agricultural Science, and the National Natural Science foundation of China (Grant No. 31530074). We greatly appreciate Prof. Liu Dingxiang from South China Agricultural University for his helpful scientific and editorial advice.

\section{Conflict of interest}

The authors declare that they have no conflict of interest.

\section{Publisher's note}

Springer Nature remains neutral with regard to jurisdictional claims in published maps and institutional affiliations.

Supplementary Information accompanies this paper at (https://doi.org/ 10.1038/s41419-019-2128-6).

Received: 25 June 2019 Revised: 14 October 2019 Accepted: 4 November 2019 
Published online: 26 November 2019

\section{References}

1. Wang, M. \& Kaufman, R. J. The impact of the endoplasmic reticulum proteinfolding environment on cancer development. Nat. Rev. Cancer 14, 581-597 (2014).

2. Schroder, M. \& Kaufman, R. J. The mammalian unfolded protein response Annu Rev. Biochem. 74, 739-789 (2005).

3. Harding, H. P. et al. An integrated stress response regulates amino acid metabolism and resistance to oxidative stress. Mol. Cell 11, 619-633 (2003).

4. Hinnebusch, A. G. \& Lorsch, J. R. The mechanism of eukaryotic translation initiation: new insights and challenges. Cold Spring Harb. Perspect. Biol. 4, a011544 (2012).

5. Ma, Y., Brewer, J. W., Diehl, J. A. \& Hendershot, L. M. Two distinct stress signaling pathways converge upon the CHOP promoter during the mammalian unfolded protein response. J. Mol. Biol. 318, 1351-1365 (2002).

6. Gale, M. Jr. \& Katze, M. G. Molecular mechanisms of interferon resistance mediated by viral-directed inhibition of PKR, the interferon-induced protein kinase. Pharm. Ther. 78, 29-46 (1998).

7. Williams, B. R. PKR; a sentinel kinase for cellular stress. Oncogene $\mathbf{1 8}, 6112-6120$ (1999).

8. Harding, H. P., Zhang, Y. \& Ron, D. Protein translation and folding are coupled by an endoplasmic-reticulum-resident kinase. Nature 397, 271-274 (1999).

9. Ye, J. et al. ER stress induces cleavage of membrane-bound ATF6 by the same proteases that process SREBPs. Mol. Cell 6, 1355-1364 (2000).

10. Yoshida, H., Matsui, T., Yamamoto, A., Okada, T. \& Mori, K. XBP1 mRNA is induced by ATF6 and spliced by IRE1 in response to ER stress to produce a highly active transcription factor. Cell 107, 881-891 (2001).

11. Yamamoto, K. et al. Transcriptional induction of mammalian ER quality control proteins is mediated by single or combined action of ATF6 alpha and XBP1. Dev. Cell 13, 365-376 (2007).

12. Hetz, C., Martinon, F., Rodriguez, D. \& Glimcher, L. H. The unfolded protein response: integrating stress signals through the stress sensor IRE1alpha. Physiol. Rev. 91, 1219-1243 (2011)

13. Calfon, $M$. et al. IRE1 couples endoplasmic reticulum load to secretory capacity by processing the XBP-1 mRNA. Nature 415, 92-96 (2002).

14. Lee, K. et al. IRE1-mediated unconventional mRNA splicing and S2P-mediated ATF6 cleavage merge to regulate XBP1 in signaling the unfolded protein response. Genes Dev. 16, 452-466 (2002).

15. Lee, A. H., Iwakoshi, N. N. \& Glimcher, L. H. XBP-1 regulates a subset of endoplasmic reticulum resident chaperone genes in the unfolded protein response. Mol. Cell. Biol. 23, 7448-7459 (2003).

16. Hollien, J. et al. Regulated Ire1-dependent decay of messenger RNAs in mammalian cells. J. Cell Biol. 186, 323-331 (2009).

17. Labbe, K. \& Saleh, M. Cell death in the host response to infection. Cell Death Differ. 15, 1339-1349 (2008).

18. Delbridge, A. R. D. \& Strasser, A. The BCL-2 protein family, BH3-mimetics and cancer therapy. Cell Death Differ. 22, 1071-1080 (2015).

19. Li, P. et al. Cytochrome $\mathrm{C}$ and dATP-dependent formation of Apaf-1/caspase-9 complex initiates an apoptotic protease cascade. Cell 91, 479-489 (1997).

20. Saito, M., Korsmeyer, S. J. \& Schlesinger, P. H. BAX-dependent transport of cytochrome c reconstituted in pure liposomes. Nat. Cell Biol. 2, 553-555 (2000).

21. Lawen, A. Apoptosis-an introduction. Bioessays 25, 888-896 (2003).

22. Wang, X. Z. et al. Identification of novel stress-induced genes downstream of chop. EMBO J. 17, 3619-3630 (1998).

23. Wang, $X$. et al. Inhibition of protein kinase $R$ activation and upregulation of GADD34 expression play a synergistic role in facilitating coronavirus replication by maintaining de novo protein synthesis in virus-infected cells. J. Virol. 83, 12462-12472 (2009).

24. McCullough, K. D., Martindale, J. L., Klotz, L. O., Aw, T. Y. \& Holbrook, N. J. Gadd153 sensitizes cells to endoplasmic reticulum stress by down-regulating $\mathrm{BCl} 2$ and perturbing the cellular redox state. Mol. Cell. Biol. 21, 1249-1259 (2001).

25. Urano, F. et al. Coupling of stress in the ER to activation of JNK protein kinases by transmembrane protein kinase IRE1. Science 287, 664-666 (2000).

26. Eferl, R. \& Wagner, E. F. AP-1: a double-edged sword in tumorigenesis. Nat. Rev. Cancer 3, 859-868 (2003).

27. Hu, P., Han, Z., Couvillon, A. D., Kaufman, R. J. \& Exton, J. H. Autocrine tumor necrosis factor alpha links endoplasmic reticulum stress to the membrane death receptor pathway through IRE1alpha-mediated NF-kappaB activation and down-regulation of TRAF2 expression. Mol. Cell. Biol. 26, 3071-3084 (2006).

28. Deng, J. et al. Translational repression mediates activation of nuclear factor kappa B by phosphorylated translation initiation factor 2. Mol. Cell. Biol. 24, 10161-10168 (2004)

29. Tam, A. B., Mercado, E. L., Hoffmann, A. \& Niwa, M. ER stress activates NFkappaB by integrating functions of basal IKK activity, IRE1 and PERK. PLOS ONE 7, e45078 (2012).

30. Ganar, K., Das, M., Sinha, S. \& Kumar, S. Newcastle disease virus: current status and our understanding. Virus Res. 184, 71-81 (2014).

31. Ecco, R., Susta, L., Afonso, C. L., Miller, P. J. \& Brown, C. Neurological lesions in chickens experimentally infected with virulent Newcastle disease virus isolates. Avian Pathol. 40, 145-152 (2011).

32. Schirrmacher, V. Oncolytic Newcastle disease virus as a prospective anti-cancer therapy. A biologic agent with potential to break therapy resistance. Expert Opin. Biol. Ther. 15, 1757-1771 (2015).

33. Tait, S. W. G. \& Green, D. R. Mitochondria and cell death: outer membrane permeabilization and beyond. Nat. Rev. Mol. Cell Biol. 11, 621-632 (2010).

34. Elankumaran, S., Rockemann, D. \& Samal, S. K. Newcastle disease virus exerts oncolysis by both intrinsic and extrinsic caspase-dependent pathways of cell death. J. Virol. 80, 7522-7534 (2006).

35. Molouki, A., Hsu, Y. T., Jahanshiri, F., Rosli, R. \& Yusoff, K. Newcastle disease virus infection promotes Bax redistribution to mitochondria and cell death in HeLa cells. Intervirology 53, 87-94 (2010).

36. Yan, Y., Liang, B., Zhang, J., Liu, Y. \& Bu, X. Apoptotic induction of lung adenocarcinoma A549 cells infected by recombinant RVG Newcastle disease virus (rL-RVG) in vitro. Mol. Med. Rep. 11, 317-326 (2015).

37. Liao, Y. et al. RIP1 is a central signaling protein in regulation of TNF-alpha/ TRAIL mediated apoptosis and necroptosis during Newcastle disease virus infection. Oncotarget 8, 43201-43217 (2017).

38. Liao, Y. et al. Regulation of de novo translation of host cells by manipulation of PERK/PKR and GADD34-PP1 activity during Newcastle disease virus infection. J. Gen. Virol. 97, 867-879 (2016).

39. Ozcan, U. et al. Chemical chaperones reduce ER stress and restore glucose homeostasis in a mouse model of type 2 diabetes. Science 313,1137-1140 (2006).

40. Liao, Y. et al. Upregulation of CHOP/GADD153 during coronavirus infectious bronchitis virus infection modulates apoptosis by restricting activation of the extracellular signal-regulated kinase pathway. J. Virol. 87, 8124-8134 (2013).

41. Fawcett, T. W., Martindale, J. L., Guyton, K. Z., Hai, T. \& Holbrook, N. J. Complexes containing activating transcription factor (ATF)/CAMP-responsive-elementbinding protein (CREB) interact with the CCAAT/enhancer-binding protein (C) EBP)-ATF composite site to regulate Gadd153 expression during the stress response. Biochem J. 339(Pt 1), 135-141 (1999).

42. Adams, J. M. \& Cory, S. The Bcl-2 protein family: arbiters of cell survival. Science 281, 1322-1326 (1998).

43. Franke, T. F., Kaplan, D. R. \& Cantley, L. C. PI3K: downstream AKTion blocks apoptosis. Cell 88, 435-437 (1997).

44. Lewis, T. S., Shapiro, P. S. \& Ahn, N. G. Signal transduction through MAP kinase cascades. Adv. Cancer Res 74, 49-139 (1998).

45. Whitmarsh, A. J. \& Davis, R. J. Structural organization of MAP-kinase signaling modules by scaffold proteins in yeast and mammals. Trends Biochem. Sci. 23 481-485 (1998).

46. Hetz, C. The unfolded protein response: controlling cell fate decisions under ER stress and beyond. Nat. Rev. Mol. Cell Biol. 13, 89-102 (2012).

47. Bubici, C., Papa, S., Pham, C. G., Zazzeroni, F. \& Franzoso, G. NF-kappaB and JNK: an intricate affair. Cell Cycle 3, 1524-1529 (2004).

48. Dhanasekaran, D. N. \& Reddy, E. P. JNK-signaling: a multiplexing hub in programmed cell death. Genes Cancer 8, 682-694 (2017).

49. Everett, H. \& McFadden, G. Apoptosis: an innate immune response to virus infection. Trends Microbiol. 7, 160-165 (1999).

50. Baltzis, D. et al. Resistance to vesicular stomatitis virus infection requires a functional cross talk between the eukaryotic translation initiation factor 2alpha kinases PERK and PKR. J. Virol. 78, 12747-12761 (2004).

51. Tardif, K. D., Waris, G. \& Siddiqui, A. Hepatitis C virus, ER stress, and oxidative stress. Trends Microbiol. 13, 159-163 (2005).

52. Chen, H. C. et al. An interconnected hierarchical model of cell death regulation by the BCL-2 family. Nat. Cell Biol. 17, 1270-1281 (2015).

53. Darling, N. J. \& Cook, S. J. The role of MAPK signalling pathways in the response to endoplasmic reticulum stress. Biochimica et. Biophysica Acta 1843 2150-2163 (2014). 
54. Chaudhari, N., Talwar, P., Pjarimisetty, A., d'Hellencourt, C. L. \& Ravanan, P. A molecular web: endoplasmic reticulum stress, inflammation, and oxidative stress. Front Cell Neurosci. 8, 213 (2014).

55. Wang, X. Z. \& Ron, D. Stress-induced phosphorylation and activation of the transcription factor CHOP (GADD153) by p38 MAP kinase. Science $\mathbf{2 7 2}$ 1347-1349 (1996).

56. Maytin, E. V., Ubeda, M., Lin, J. C. \& Habener, J. F. Stress-inducible transcription factor $\mathrm{CHOP} /$ gadd153 induces apoptosis in mammalian cells via p38 kinasedependent and -independent mechanisms. Exp. Cell Res. 267, 193-204 (2001).

57. Wu, J., He, G. T., Zhang, W. J., Xu, J. \& Huang, Q. B. IRE1alpha signaling pathways involved in mammalian cell fate determination. Cell Physiol. Biochem. 38, 847-858 (2016).

58. Hassan, I. H. et al. Influenza A viral replication is blocked by inhibition of the inositol-requiring enzyme 1 (IRE1) stress pathway. J. Biol. Chem. 287, 4679-4689 (2012).
59. Chan, S. W. \& Egan, P. A. Hepatitis C virus envelope proteins regulate CHOP via induction of the unfolded protein response. Faseb J. 19, 1510-+ (2005)

60. Li, B. et al. Hepatitis B virus $X$ protein $(\mathrm{HBX})$ activates ATF6 and IRE1-XBP1 pathways of unfolded protein response. Virus Res. 124, 44-49 (2007).

61. Yu, C. Y., Hsu, Y. W., Liao, C. L. \& Lin, Y. L. Flavivirus infection activates the XBP1 pathway of the unfolded protein response to cope with endoplasmic reticulum stress. J. Virol. 80, 11868-11880 (2006).

62. Sharma, M. et al. Japanese encephalitis virus activates autophagy through XBP1 and ATF6 ER stress sensors in neuronal cells. J. Gen. Virol. 98, 1027-1039 (2017)

63. Trujillo-Alonso, V., Maruri-Avidal, L., Arias, C. F. \& Lopez, S. Rotavirus infection induces the unfolded protein response of the cell and controls it through the nonstructural protein NSP3. J. Virol. 85, 12594-12604 (2011).

64. Sriburi, R., Jackowski, S., Mori, K. \& Brewer, J. W. XBP1: a link between the unfolded protein response, lipid biosynthesis, and biogenesis of the endoplasmic reticulum. J. Cell Biol. 167, 35-41 (2004). 